\title{
The Application of Normal Phase Liquid Chromatography/Mass Spectrometry By Using Coaxial Continuous Flow Fast Atom Bombardment
}

\author{
David L. Lawrence \\ The Frocter \& Gamble Company, Human \& Environmental Safety Department, Cincinnati, Ohio, USA
}

\begin{abstract}
This article describes the interfacing of a normal phase fused silica capillary high performance liquid chromatography system to a magnetic sector mass spectrometer by using continuous flow fast atom bombardment (CFFAB). While the performance of CFFAB using reversed phase techniques is well understood, there is very little if any documentation on interfacing nonaqueous normal phase systems with CFFAB. This article describes the use of packed fused silica capillary liquid chromatography columns and the corresponding normal phase solvent systems. The experimental parameters required with nonaqueous solvent systems differ significantly from those of aqueous solvent systems. Ditallowdimethylammonium chloride (DTDMAC), a cationic surfactant commonly used as the active ingredient in fabric softener products, was chosen as a model compound to demonstrate the technique. DTDMAC was identified in a commercially available fabric softener product by using on-line normal phase liquid chromatography/mass spectrometry with accurate mass and tandem mass spectrometry. (J Am Soc Mass Spectrom 1992, 3, 575-581)
\end{abstract}

S ince its introduction in 1985 by Ito et al. [1] and by Caprioli et al. [2], Frit-fast atom bombardment (FAB) or continuous flow FAB (CFFAB) has been developed continuously as an interface for liquid chromatography/mass spectrometry (LC/MS). A wide range of configurations is used to reduce the amount of liquid flowing into the mass spectrometer to an acceptable level $(<10 \mathrm{uL} / \mathrm{m})$. Typical configurations have included the use of microbore LC columns with low flow rates [3], standard and microbore LC columns at traditional flow rates utilizing effluent splitting devices [4-10], and packed fused silica and open tubular capillary columns of internal diameters ranging from $.05-0.32 \mathrm{~mm}$ and operated at flow rates of $50 \mathrm{~nL} / \mathrm{m}$ to $10 \mathrm{uL} / \mathrm{m}$ [9-17]. A variety of matrix addition schemes is also used. Examples of these include direct addition to the mobile phase [3-8, 14-18], postcolumn addition through a mixing Tee [9. 10], and postcolumn coaxial matrix addition [11-13]. The relative merits of postcolumn versus precolumn matrix addition have been described [19]. The configuration described in this article (Figure 1) utilizes postcolumn coaxial matrix addition similar to that described by Moseley et al. [11].

Address reprint requests to The Procter \& Gamble Company, Human \& Environmental Safety Department, 5299 Spring Grove Avenue, Cincinnati, OH 45217.
Cationic surfactants are a rapidly growing class of compounds that find wide use in fabric softeners [20, 21]. Cationic surfactants, specifically, quaternary ammonium salts, are preformed ions and are thus well suited to analysis by FAB [20]. Quaternary ammonium salts have even been studied by FAB-tandem mass spectrometry (MS/MS) [21, 22]. The compound of interest in this study is ditallowdimethylammonium chloride (DTDMAC). DTDMAC is a mixture of various combinations of tallow $\left(C_{14,16,18}\right)$ alkyl homologs. Commercially prepared DTDMAC also contains low levels of monotallowtrimethylammonium chloride (MTTMAC) and tritallowmethylammonium chloride (TTMAC). The solubility characteristics of these higher molecular weight cationic surfactants preclude analysis by reversed phase LC but make them excellent candidates for analysis by normal phase LC. Herein, we describe the analysis of DTDMAC by using normal phase LC.

\section{Experimental}

\section{Chemicals}

Glycerol, methanol, chloroform, and hexane (high performance liquid chromatography grade) were supplied by Fisher Scientific (Cincinnati, OH). Polyethylene glycol with an average molecular weight of 400 


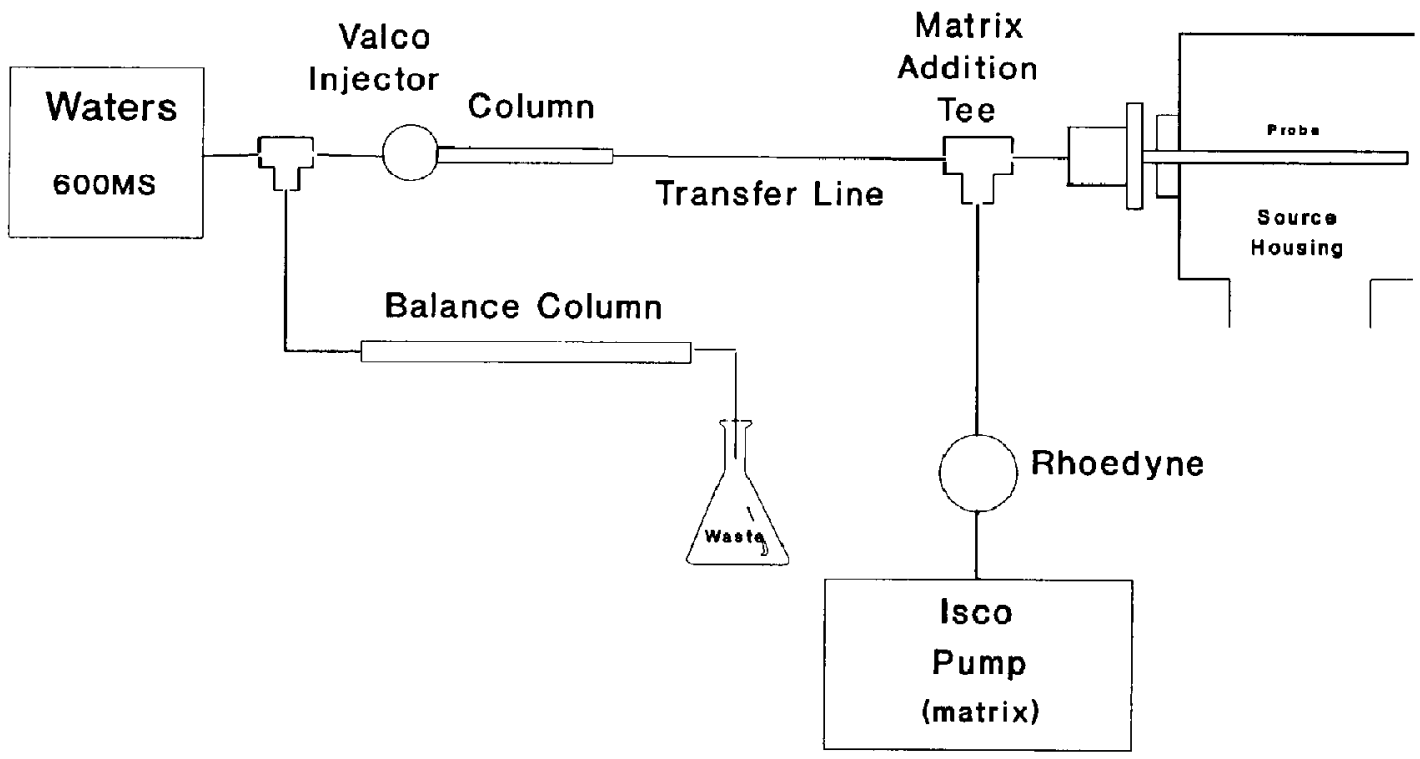

Figure 1. Schematic of CFFAB LC/MS interface.

(PEG400) was purchased from Sigma Chcmical Company (St. Louis, MO). DTDMAC was supplied by Akzo Chemicals (McCook, IL), Lot \# 1189312M06. A commercially available fabric softener product was purchased at a local supermarket.

\section{Mass Spectrometry}

Measurements were carried out on a double-focusing sectur mass spectrometer (Model 70-VSE, VG Analytical Ltd, Altrincham, UK) by using a CFFAB source and operated at $+6 \mathrm{kV}$ accelerating voltage. Secondary ions were produced by using a primary beam of positively charged cesium ions at energies of 25 $\mathrm{keV}$. The mass resolving power was typically operated in the range of $1000-5000$ ( $10 \%$ valley definition). The operating pressure of the instrument was monitored with the analyzer ion gauge located between the ion source and the electrostatic analyzer and was maintained at $-3 \times 10^{-6}$ torr. The ion source ion gauge was turned off during CFFAB experiments. The ion source heater was not used. The magnet was scanned exponentially from 1550 to 300 at $2 \mathrm{~s} / \mathrm{d}$ for nominal mass studies. This mass range was selected to accommodate concurrent projects which required a higher mass range. The lower mass limit of $\mathrm{m} / \mathrm{z} 300$ is used to reduce the chemical noise from the glycerol matrix. For accurate mass studies the magnet was scanned from $800-300 @ 5 \mathrm{~s} / \mathrm{d}$. Secondary mass reference was achieved by adding PEG400 at $1 \%$ to the matrix solution. MS/MS studies were accomplished by using $B / E$ linked scanning techniques [23]. Collisional activation in the first field free region of the mass spectrometer was achieved by using heliurn at a pressure that attenuated the main beam by $25 \%$.

\section{Liquid Chromatography}

Gradient separations were under control of a Waters 600MS pumping system (Millipore Corp., Waters Chromatography Division, Milford, MA). The flow rate of the gradient entering the mass spectrometer was reduced to $-3-4 \mathrm{uL} / \mathrm{m}$ by using a splitter (similar in design to that described by Coutant et al. [9, 10]) upstream of the fixed internal volume injector valve (Valco $\mathrm{C} 14 \mathrm{~W}$ ). This allows the gradient to be controlled at higher, traditional flow rates of $0.8-1.0$ $\mathrm{mL} / \mathrm{m}$. Injector volumes of $60 \mathrm{~nL}$ and $100 \mathrm{~nL}$ were used. Mobile phase A contained chloroform/hexane/ acetic acid (80/20/0.5) and mobile phase B contained chloroform $/ \mathrm{methanol} /$ acetic acid $(50 / 50 / 0.5)$. The gradient was from $95 \% \mathrm{~A}$ to $80 \% \mathrm{~A}$ over $18 \mathrm{~m}$ and holding for $14 \mathrm{~m}$. An Isco Model uLC-500 syringe pump (Isco, Inc., Lincoln, NE) was used for postcolumn addition of the matrix solution at a flow rate of 1 $\mathbf{u L} / \mathbf{m}$.

The columns used in this article were prepared in our lab by using slurry packing techniques. Columns were fabricated from $0.250 \mathrm{~mm}$ ID by $20-30-\mathrm{cm}$ long fused silica tubing (Restek Corp., Port Matilda, PA) and were attached to a $0.050 \mathrm{~mm}$ ID $(0.200 \mathrm{~mm}$ OD) $\times 1 \mathrm{M}$ fused silica transfer line (SGE, Austin, TX) (see Figure 1). The columns were packed with $5 \mu$ amino particles (Phase Sep, Norwalk, CT). The sheath tube for the coaxial matrix addition tee was fabricated 
from $0.50 \mathrm{~mm}$ OD $\times 0.250 \mathrm{~mm}$ ID fused silica tubing (Polymicro Technologies, Phoenix, AZ).

\section{Sample Preparation}

A stock solution of $116.4 \mathrm{mg}$ DTDMAC was prepared in $100 \mathrm{~mL}$ methanol. A $100 \mathrm{uL}$ aliquot was further diluted to $1 \mathrm{~mL}$ with mobile phase $\mathrm{A}$, yielding a 116 $\mathrm{ng} / \mathrm{uL}$ solution of DTDMAC. A $1 \mathrm{~g}$ aliquot of the fabric softener product was dried under a stream of nitrogen then taken up in $5 \mathrm{~mL}$ mobile phase $\mathrm{A}$.

\section{Results and Discussion}

\section{System Parameters}

One key to successful CFFAB LC/MS experiments is to maintain a stable ion beam in the mass spectrometer. While Henion and co-workers [24] have reported using nonpolar solvents with electrospray ionization, the overwhelming majority, if not all, the literature references to CFFAB LC/MS utilize reversed (or aqueous) phase solvent systems. The key parameters are (1) delivering the correct amount of matrix (typically $1-20 \%$ aqueous glycerol) to the probe tip and (2) maintaining the temperature of the probe tip so that the water in the mobile phase and matrix solutions does not freeze but not so high such that the matrix is volatilized too rapidly. The use of organic or normal phase solvent systems imposes different requirements for these parameters. A key requirement is to make the matrix solution compatible with nonaqueous solvents. The mobile phase compositions used included chloroform/methanol $(50 / 50)$ and chloroform/hexane $(80 / 20)$. The composition of the matrix solution used in this article to provide solvent compatibility was glycerol/methanol 75/25. Extremely unstable ion currents and ion gauge readings were observed with lower concentrations of glycerol (10-25\%) or if aqueous base glycerol solutions were used. It is believed that the much higher volatility of these mobile phase solutions as compared to those used in reversed phase solvents results in extremely fast, even violent, evaporation from the probe tip under vacuum, resulting in erratic pressure surges with associated instabilities of the ion currents. The more viscous, higher glycerol content matrix solution prevents this problem by controlling the evaporation rate, resulting in a very stable vacuum and very stable ion currents. The probe temperature parameter becomes unimportant under these

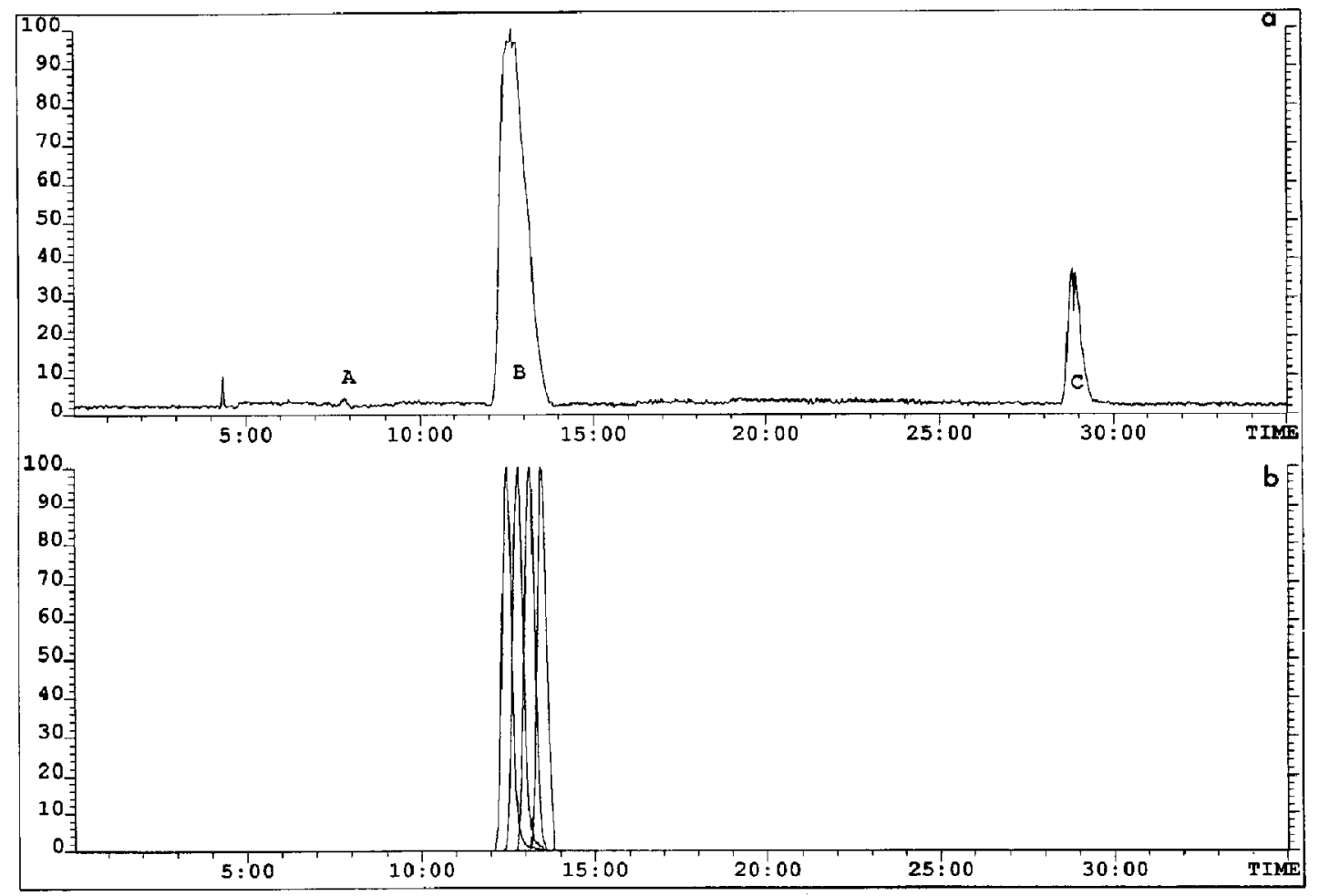

Figure 2. (a) Reconstructed ion chromatogram (RIC) of DTDMAC. (b) Extracted ion profile (EIP) of independently normalized ions of $m / z$ 550, 522, 494, and 466 (DTDMA ${ }^{+}$homologs 18/18, $18 / 16,16 / 16$ and $16 / 14$, respectively). 

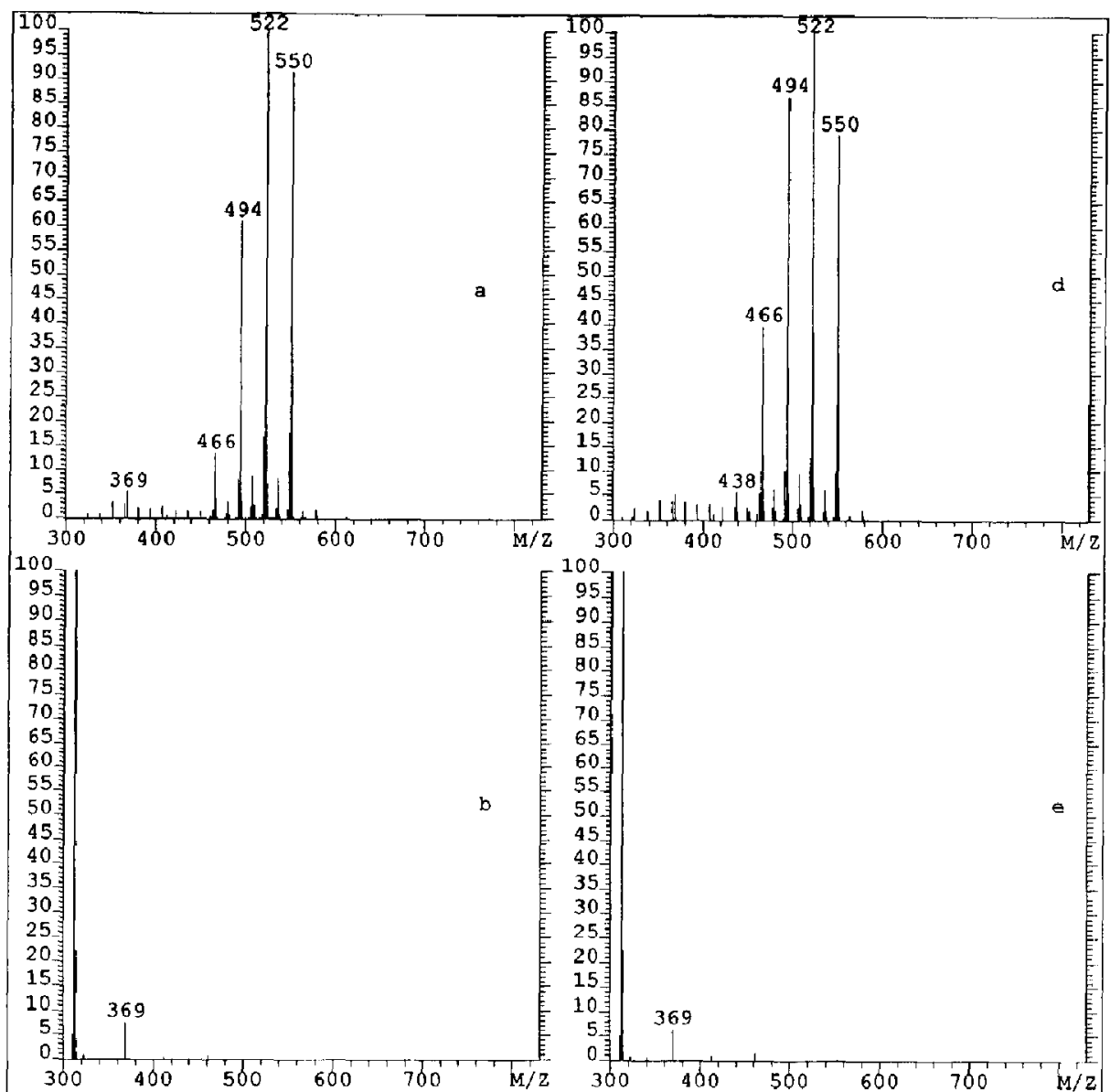

$-1007$

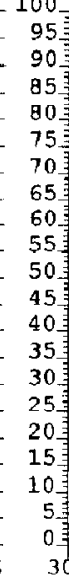

事

85

80 要

70 辛

65

55 录

50

40 要

35

30 永

20

15侸

5. 369

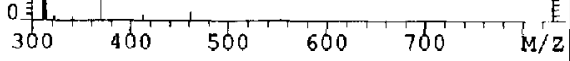

100

95
90
95

80

75

70 音

60 㝵

50 争

40 寻

35

25毒

20

10

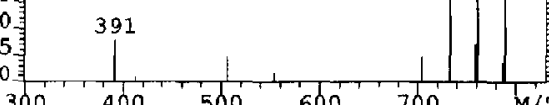

100

95 沓
90 辛
85

80 章

75

70
65
60
5

609
55

c

1/z $\quad 300$

Figure 3. (a-c) Spectra for peaks A, B, and C, respectively, of DTDMAC analysis (Figure 3). (d-f) Averaged spectra for peaks $A, B$, and $C$ of the commercial fabric softener analysis (Figure 4), 
conditions because there is no water to freeze at the probe tip.

\section{Sample Analysis}

DTDMAC was analyzed by CFFAB-LC/MS. The resulting RIC chromatogram is shown in Figure 2. The spectrum averaged across peak $B$ is shown in Figure $3 a$ and is typical of the tallow distribution of DTDMA ${ }^{+}$ ions. Ions of $m / z 466,494,522$, and 550 correspond to the $C_{14 / 16}, C_{16 / 16}$ and 14/18, $C_{16 / 18}$, and $C_{18 / 18}$ alkyl homologs, respectively $[20,21]$. The spectrum of peak $C$ (Figure 3b) shows a prominent ion of $\mathrm{m} / \mathrm{z} 312$ corresponding to the $C_{18}-$ MTTMA $^{+}$impurity. The magnet was not scanned low enough to observe other $\mathrm{MTTMA}^{+}$homologs. A series of ions of $\mathrm{m} / \mathrm{z} 704$, 732,760 , and 788 appear in the averaged, background subtracted spectrum of peak A (Figure $3 \mathrm{c}$ ), which correspond to the various combinations of tallow homologs of the TTMA $^{+}$impurity. The somewhat broadened appearance of the DTDMA ${ }^{+}$peak may be explained by the partial separation ( $\sim 50 \%$ baseline) of the DTDMA ${ }^{+}$homologs on the LC column. This is illustrated in Figure $2 b$, where the extracted ion profiles (EIP) for the DTDMA ${ }^{+}$homologs (order of elution $-m / z 550,522,494$, and 466) are independently normalized and coplotted. The peak widths of the individual homologs are more consistent with that observed with peak $\mathrm{C}$ in the chromatogram.
The fabric softener product extract was analyzed on a later date under similar LC conditions and gave a similar pattern of peaks (Figure 4). The corresponding averaged mass spectra for peaks $A, B$, and $C$ are shown in Figure $3 \mathrm{~d}-\mathrm{f}$ with striking similarity to the spectra obtained from the DTDMAC standard. In the case of the commercial product, the DTDMAC and TTMAC homolog distributions are slightly different, as indicated by higher intensities of $m / z 466$ and 704 ions in Figure $3 \mathrm{~d}$ and $\mathrm{f}$, respectively.

Accurate mass determinations of the product extract were made by using on-line LC/MS. Addition of $1 \%$ PEG400 to the matrix solution provided secondary reference ions at intervals of $44 \mathrm{u}$ to facilitate accurate mass measurements (Figure 5). The accurate mass results of triplicate analyses of the product extract are shown in Table 1. The mass measurement errors were consistently less than $10 \mathrm{ppm}$.

As further confirmation of the DTDMA ${ }^{+}$structures, LC/MS/MS analyses using $\mathrm{B} / \mathrm{E}$ linked scans were conducted to obtain product ion spectra. The product ion spectra of four precursor ions were taken sequentially throughout the LC/MS analysis. The selected precursor ions were of $m / z 788$ (TTMA $\left.^{+}\right), m / z$ 312 (MTTMA $^{+}$), and $m / z 522$ and 550 (DTDMA ${ }^{+}$ homologs). The reconstructed precursor ion chromatograms are shown superimposed in Figure 6a. The product ion spectra for the DTDMA ${ }^{+}$homologs are shown in Figure $6 \mathrm{~b}$ and $\mathrm{c}$. These product ion

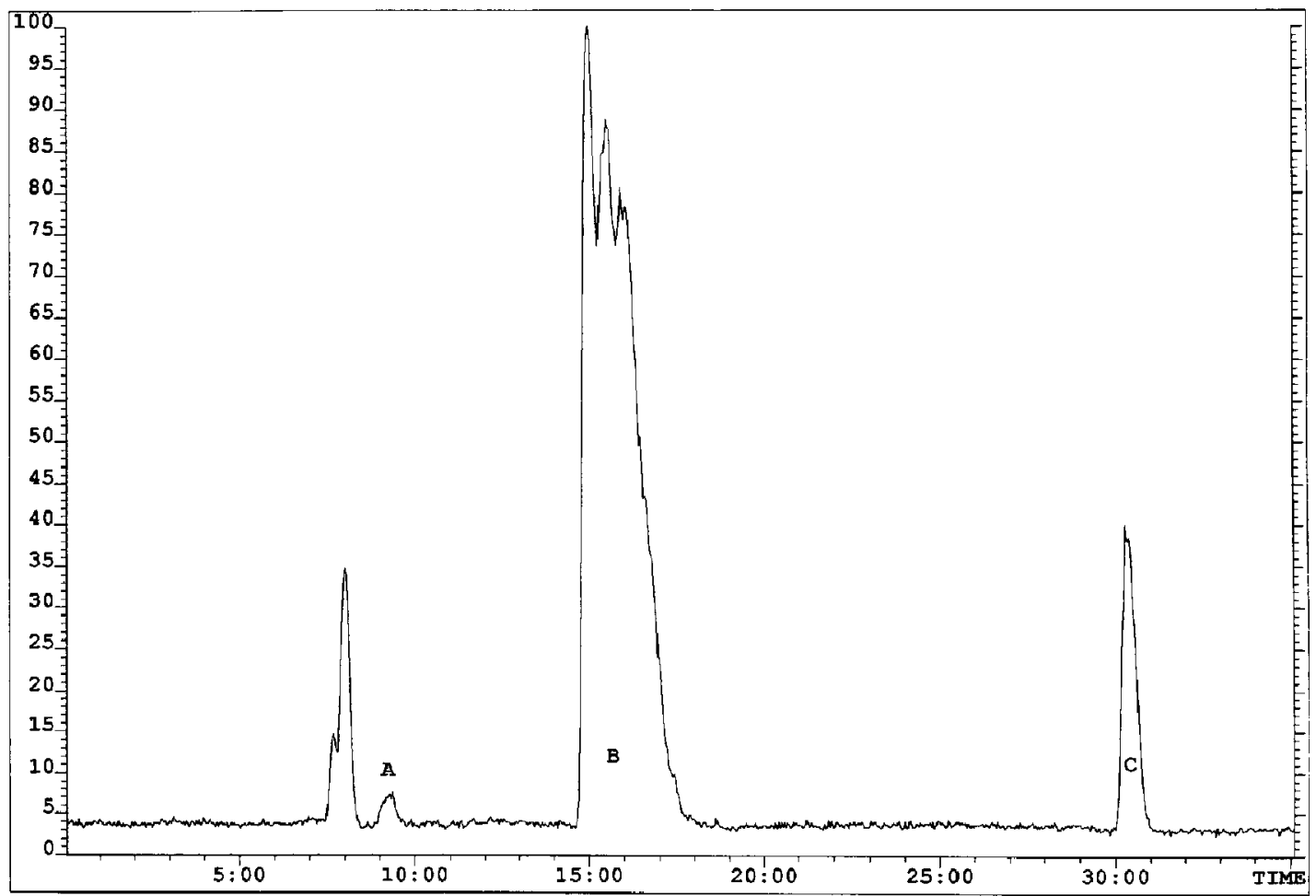

Figure 4. RIC of commercial fabric softener product. 


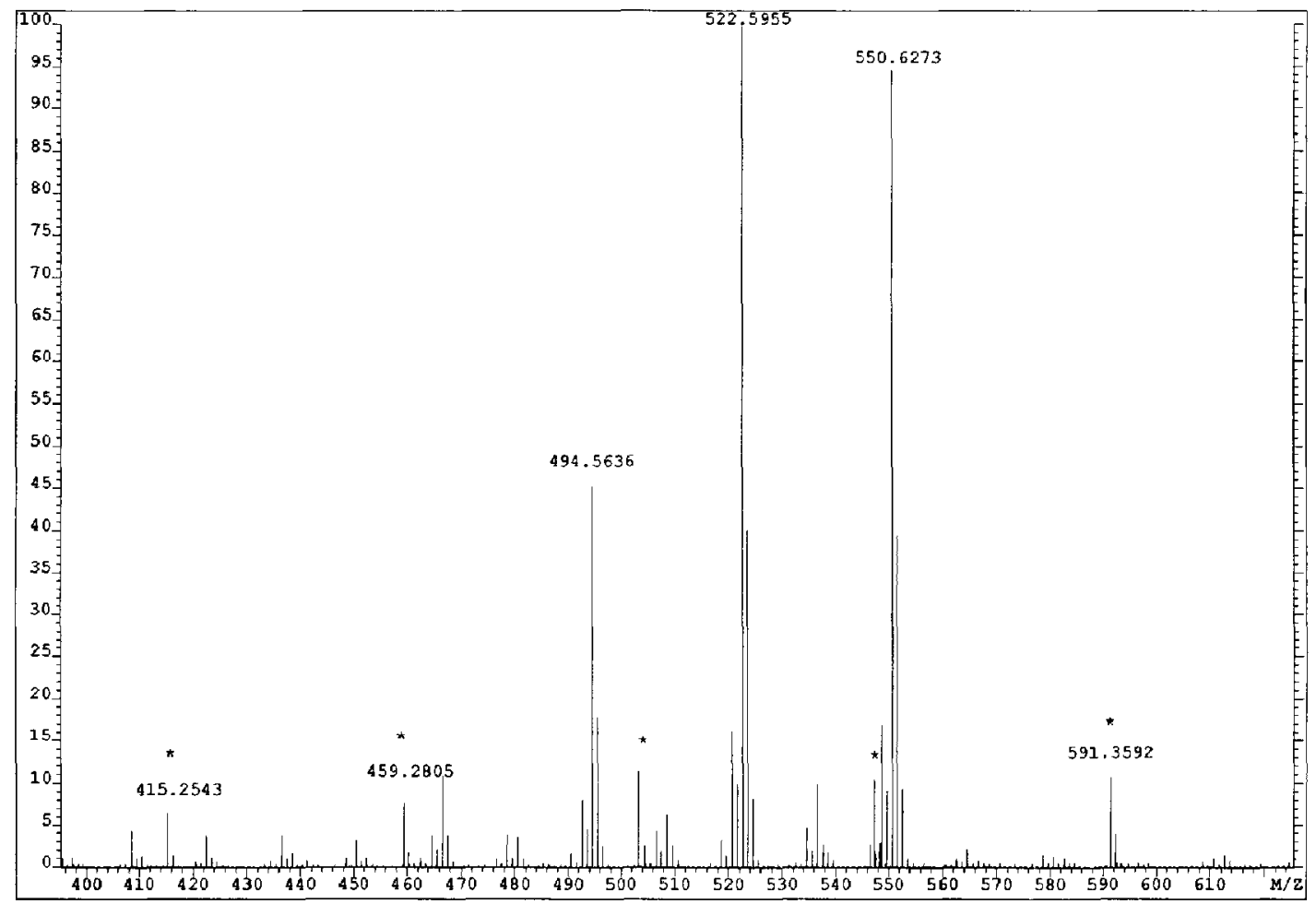

Figure 5. Accurate mass spectrum averaged across the DTDM $\Lambda^{+}$peak in the LC/MS analysis of the commercial fabric softener product. The PEG reference ions are marked with an asterisk.

spectra illustrate proximate and remote site fragmentations. In Figure $6 \mathrm{~b}$, the most prominent fragment ion of $\mathrm{m} / \mathrm{z} 296$ results from the loss of neutral octadecane from the molecular cation of $m / z 550$. In Figure $6 \mathrm{c}$, the ions of $\mathrm{m} / \mathrm{z} 268$ and 296 indicate the loss of neutral octadecane and hexadecane, respectively, from the molecular cation of $m / z 522$, thus characterizing the side chains as $C_{16}$ and $C_{18}$. These CAD fragmentations for DTDMAC and for dimethyldicocoammonium chloride were observed previously [21, 22]. Remote site fragmentations are evident in both spectra, resulting in the losses of $\mathrm{C}_{\mathbf{n}} \mathrm{H}_{2 \mathrm{n}+2}$ from the molecular

Table 1. Accurate mass data for DTDMAC in commercial fabric softener

\begin{tabular}{ccccr}
\hline Analysis & Homolog & $\begin{array}{c}\text { Theoretical } \\
\text { mass }\end{array}$ & Measured mass & $\begin{array}{c}\text { Error } \\
\text { (ppm) }\end{array}$ \\
\hline \hline 1 & $18 / 18$ & 550.6291 & 550.6278 & 2.4 \\
2 & & & 550.6282 & 1.6 \\
3 & & & 560.6273 & 3.3 \\
1 & \multirow{2}{*}{$18 / 16$} & 522.5978 & 522.6020 & -8.0 \\
2 & & & 522.5999 & -4.0 \\
3 & & & 522.5955 & 4.2 \\
1 & \multirow{2}{*}{$16 / 16$} & 494.5665 & 494.5699 & -6.9 \\
2 & & & 494.5675 & -2.0 \\
3 & & & 494.5636 & 5.9 \\
\hline
\end{tabular}

cation and appearing as a sort of picket fence between the remote site fragment ions and the parent ion [25].

\section{Conclusions}

This study demonstrates that normal phase solvent systems work well with CFFAB-LC/MS. The range of applications of CFFAB-LC/MS is expanded by the ability to analyze the higher molecular weight cationic surfactants that exhibit pour sulubility in polar solvents and, consequently, are not amenable to reversed phase LC analysis. Normal phase separations have been used for more than $95 \%$ of our instrument time since August 1989, and attests to the ruggedness and reliability of the system. Surprisingly very little source contamination has been experienced. The primary maintenance considerations have been more frequent oil changes for the roughing pumps and more frequent cleaning of the ceramic insulators in the cesium ion gun.

\section{Acknowledgments}

The author thanks Jim Ward, Alice Vogel, and Barb Modafari for help in developing LC separations and for supplying the extract of the fabric softener product. I gratefully acknowledge Dennis Shelly, Lance Nicolaysen, Billy Moore, and Margy Conditt for their contributions and helpful discussions. Finally, I thank Roger Hayes, Billy Moore, and Rob Rapaport for critically reviewing this manuscript prior to submission. 

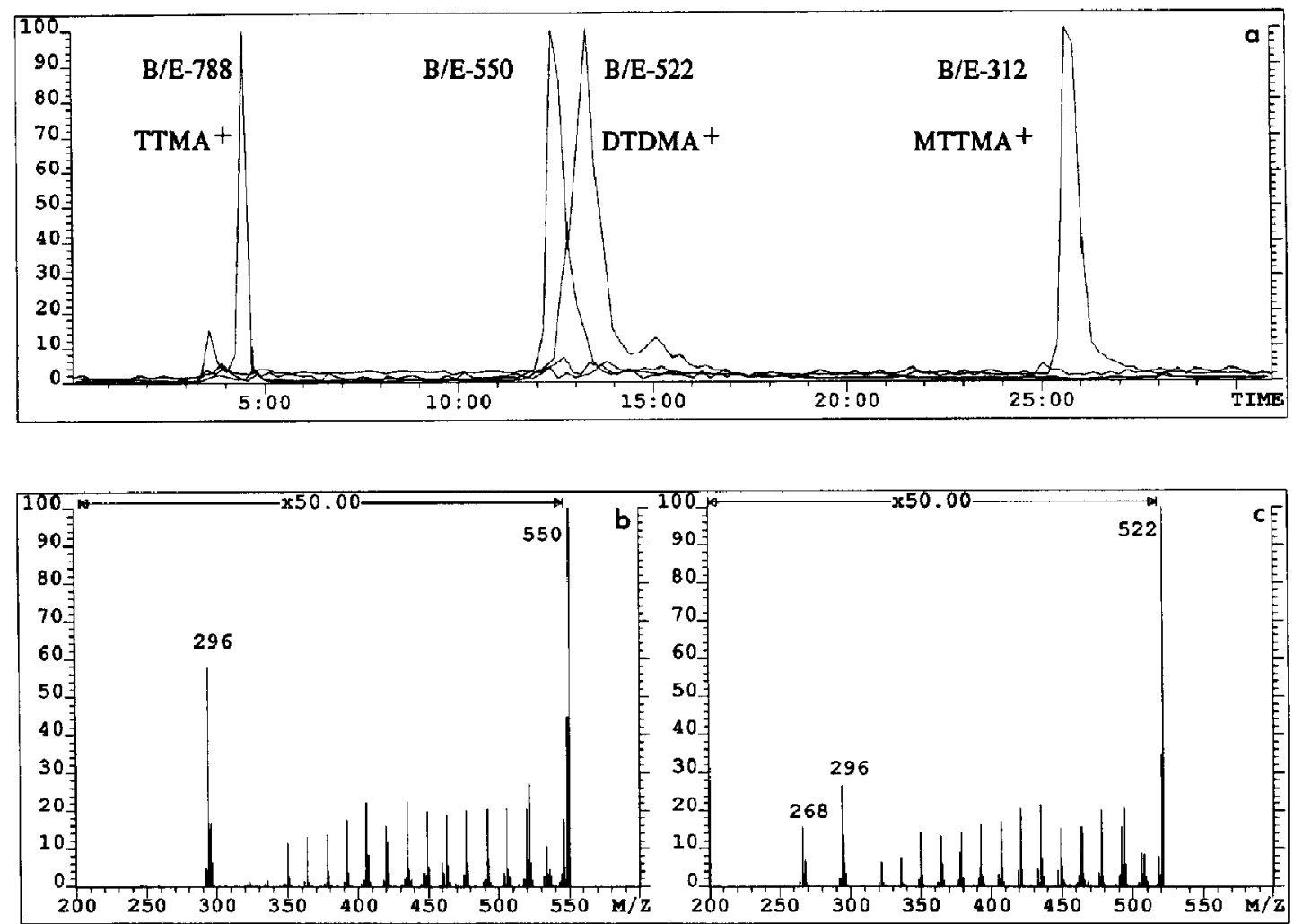

Figure 6. (a) RICs of precursor ions of $m / z$ 788, 550, 522, and 312. (b) Product ion spectrum of the precursor ion of $m / z$ 550. (c) Product ion spectrum of the precursor ion of $m / z 522$.

\section{References}

1. Ito, Y; Takeuchi, T.; Ishii, D.; Goto, M.; Mizuno, T. I. Chromatogr. 1986, 358, 201-207.

2. Caprioli, R. M.; Fan, T.; Cottrell, J. S. Anal, Chem. 1986, 58 , 2949.

3. Caprioli, R. M.; Moore, W. T.; DaGue, B.; Martin, M. J. Chromatogr. 1988, 443, 355-362.

4. Hutchinson, D. W.; Woolfitt, A. R.; Ashcroft, A. E. Org. Mass Spectrom. 1987, 22, 304-306.

5. Kokkonen, P.; Niessen, W. M. A.; Tjaden, U. R.; Van der Greef, J. J. Chromatogr. 1989, 474, 59-68.

6. Kokkonen, P.; Niessen, W. M. A.; Tjaden, U. R.; ten Hove, G. J.; van de Werken, G. Rapid Commun. Mass Spectrom. 1989, 3, 102-106.

7. Takeuchi, T.; Watanabe, S.; Kondo, N.; Ishii, D. J. Chromatogr. 1988, 435, 482-488.

8. Hattori, M.; Kawata Y.; Kakiuchi, N.; Matsuura, K.; Namba, T. Shoyakugaku Zasshi 1988, 42, 228-235.

9. Coutant, J. E.; Chen, T.; Ackermann, B. L. Presented at the 37th ASMS Conference on Mass Spectrometry and Allied Topics, Miami Beach, FL, May 21-26, 1989.

10. Coutant, J. E.; Teng-Man Chen; Ackermann, B. L. T. of Chrom. 1990, 529, 265-275.

11. Moseley, M. A.; Deterding, L. J.; de Wit, J. S. M.; Tomer, K. B.; Kennedy, R. T.; Bragg, N.; Jorgenson, J. W. Anal. Chem. 1989, 61, 1577-1584.

12. Moseley, M. A.; Deterding, L. J.; Tomer, K. B.; Jorgenson, J. W. J. Chromatogr. 1989, 480, 197-209.
13. Moseley, M. A.; Deterding, L. J.; Tomer, K. B.; Jorgenson, J. W. Anal. Chem. 1991, 63, 1467-1473.

14. Boulenguer, P.; Leroy, Y.; Alonzo, J. M.; Montreuil, J.; Ricart, G.; Colbert, C.; Duquet, D.; Dewaele, C.; Fournet, B. Anal. Biochem. 1988, 168, 164-170.

15. Ito, Y.; Takeuchi, T.; Ishii, D.; Goto, M.; Mizuno, T. J. Chromatogr. 1987, 391, 296-302.

16. Barefoot, A. C.; Reiser, R. W.; Cousins, S. A. J. Chromatogr. 1989, 474, 39-50.

17. Norwood, D. L.; Kodo, N.; Millington, D. S. Rapid Commun. Mass Spectrom. 1988, 2, 269-272.

18. Millington, D. S.; Norwood, D. L.; Kodo, N.; Roe, C. R.; Inoue, F. Anal. Biochem. 1989, 180, 331-339.

19. Pleasance, S.; Thibault, P.; Moseley, M. A.; Deterding, L. J.; Tomer, K. B.; Jorgenson, J. W. J, Am. Soc. Mass Spec. trom. 1990, 1, 312-319.

20. Simms, J. R.; Keough, T.; Ward, S. R.; Moore, B. L.; Bandurraga, M. M. Anal. Chem. 1988, 60, 2613.

21. Lyon, P. A.; Crow, F. W.; Tomer, K. B.; Gross, M. L. Anal. Chem. 1984, 56, 2278-2284.

22. Fraley, D. F.; Lawrence, D. L. Proceedings of the 33rd Conference on Mass Spectrometry and Allied Topics, San Diego, CA, 1985.

23. Weston, A. F.; Jennings, K. R.; Evans, R. M. Int. J. Mass Spectrom. Ion Phys. 1976, 20, 317.

24. Duffin, K. L.; Henion, J. D.; Shieh, J. J. Anal. Chem. 1991, 63, 1781-1786.

25. Jensen, N.; Tomer, K.; Gross, M. J. Amer. Chem. Soc. 1985, $107,1863$. 